\title{
Minimally invasive therapies for hepatocellular carcinoma: narrowing the gaps
}

\author{
Kevin M. Sullivan', Raymond S. Yeung ${ }^{1,2}$ \\ 1Department of Surgery, University of Washington, Seattle, WA 98195, USA. \\ ${ }^{2}$ Center for Advanced Minimally Invasive Liver Oncologic Therapies (CAMILOT), University of Washington, Seattle, WA 98195, USA.
}

Correspondence to: Dr. Raymond S. Yeung, Department of Surgery, University of Washington, 1959 NE Pacific, Seattle, WA 98195, USA. E-mail: ryeung@uw.edu

How to cite this article: Sullivan KM, Yeung RS. Minimally invasive therapies for hepatocellular carcinoma: narrowing the gaps. Hepatoma Res 2018;4:68. http://dx.doi.org/10.20517/2394-5079.2018.95

Received: 21 Aug 2018 First Decision: 9 Oct 2018 Revised: 18 Oct 2018 Accepted: 18 Oct 2018 Published: 25 Oct 2018

Science Editor: Guang-Wen Cao Copy Editor: Cai-Hong Wang Production Editor: Zhong-Yu Guo

\begin{abstract}
With increasing awareness of the HCC epidemic around the globe, early diagnosis of tumors provides a greater opportunity to benefit patients from liver-directed treatments including surgical resection, ablation, catheter-based therapies and external beam radiation. Development of new approaches and refinement of existing techniques have improved our capabilities to provide efficacious and safe means of local disease control. The choice of treatment for individual patients hinges heavily on factors related to the tumor, underlying hepatic function, and existing co-morbidities. Recent advances in minimally invasive therapies across all disciplines have augmented our ability to eradicate the tumor while preserving liver parenchyma. In this review, we discuss and summarize current minimally invasive options that are available to treat HCCs that are confirmed to the liver, especially in their early stages. Emerging evidence suggest that resection, ablation and radiation can all provide excellent local control, and this opens more options for patients to best suit their needs.
\end{abstract}

Keywords: Resection, ablation, chemoembolization, radioembolization, Yttrium-90, radiation, laparoscopic, robotic

\section{INTRODUCTION}

Hepatocellular carcinoma (HCC) has the sixth highest cancer incidence and is the fourth most common cause of cancer-related mortality worldwide ${ }^{[1]}$. In the United States, the average annual percent change in the cancer-related death rate for HCC increased 2.8\% from 2003 to 2012, compared to a decrease in the average annual percent change in cancer-related death for the majority of the other top causes of cancerrelated death ${ }^{[2]}$. Common causes of HCC are cirrhosis due to hepatitis B virus, hepatitis C virus (HCV), or alcoholic hepatitis, with less common etiologies including hereditary diseases such as hemochromatosis or

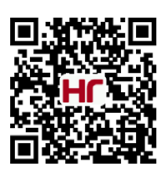


liver damage due to toxins like aflatoxin. Chronic liver disease caused by HCV is a significant contributor to the rising trend in Western countries although widespread adoption of effective anti-hepatitis C treatments using direct antiviral agents is beginning to reduce the number of HCV-related HCC cases. Yet, a much larger threat stemming from non-alcoholic steatohepatitis (NASH) will continue to promote the incidence of HCC worldwide as the obesity pandemic reaches all corners of the globe. Unlike those with cirrhosis secondary to viral hepatitis or alcohol abuse, the surveillance for HCC in the setting of noncirrhotic NASH remains uncertain and without established guidelines. Much effort is focused on finding cost-effective methods such as ultrasound evaluation and serum alpha-fetoprotein (AFP) measurement for early cancer detection in this high-risk group with the understanding that the stage at which HCC is diagnosed strongly influences the outcome of the disease.

As the majority of HCCs remain confined to the liver without distant metastases at the time of diagnosis, liver-directed loco-regional approaches are the mainstay of current treatments. Over the last two decades, the field has witnessed remarkable advances in many areas involving surgery, interventional radiology, radiation oncology, and medical oncology, which are re-shaping the landscape of HCC treatments. In this review, we will highlight progress made in minimally invasive techniques that are currently in use, with the objective of comparing their efficacy based on available evidence. Due to the wide-ranging disciplines and technical demands of individual treatment modalities, we strongly endorse an up-front multi-disciplinary discussion for every case of newly diagnosed HCC. In our Liver Tumor Clinic at the University of Washington, each patient is provided with a consensus recommendation from our multidisciplinary group consisting of surgeons, radiologists, interventional radiologists, medical oncologists, and radiation oncologists. This approach is continued longitudinally to ensure the most appropriate management given the high risk of recurrent disease. While many patients are considered for liver transplantation, only a limited number undergo such procedure due to organ availability and variable drop-out rates. For those with good liver reserve and limited tumor burden, definitive loco-regional therapies provide excellent disease control. Here, we will summarize recent developments in minimally invasive modalities and their relative efficacy in the treatment of HCC.

\section{ADVANCES IN LIVER-DIRECTED THERAPIES}

\section{Minimally invasive techniques for hepatic resection}

Surgical resection has remained the gold standard for treatment of localized hepatocellular carcinoma in patients with good liver reserve (i.e., Child's A, B7) and without significant portal hypertension (i.e., hepatic venous pressure gradient $<10 \mathrm{mmHg}$, platelet count $>100,000 / \mu \mathrm{L})$. Other factors to be considered include the tumor stage [usually Barcelona Clinic Liver Cancer (BCLC) 0, A], tumor biology, and patient's medical comorbidities. The presence of vascular invasion by the tumor and high AFP levels are predictors of poor outcome, and such cases should be thoroughly discussed by a multi-disciplinary tumor board before deciding on surgical resection.

Traditionally, hepatic resection has been performed as an open operation using a variety of abdominal incisions, which are associated with major morbidities. Advances in surgical technique including the application of minimally invasive approaches have significantly reduced morbidities following hepatectomy. Laparoscopic hepatobiliary surgery carries the same advantages of minimally invasive surgery in all other realms, namely decreased length of hospitalization, reduced wound complications, and improved postoperative pain, which translate to faster resumption of normal activities. Another notable benefit of laparoscopic hepatic surgery is the tamponade effect created by the carbon dioxide insufflation to reduce hemorrhage from hepatic venous branches. Placement of patient in reverse Trendelenburg position also aims to minimize blood loss by decreasing venous pressure. Early reports of laparoscopic hepatectomy confirmed that the approach was safe with minimal mortality and produced comparable overall survival (OS) and disease-free survival (DFS) to open hepatectomy ${ }^{[3-5]}$. In cirrhotic 
livers, there is suggestion of reduced post-operative ascites following laparoscopic resection. Subsequent large systematic reviews of laparoscopic $v s$. open hepatectomy for malignant disease further demonstrated decreased intraoperative blood loss and transfusion requirements, shorter length of hospitalization, and fewer overall complications ${ }^{[6-8]}$. With regards to oncologic outcomes in HCC, compared to open resection, laparoscopic resection showed no difference in 1-, 3-, and 5-year OS and DFS ${ }^{[9]}$. The indications for laparoscopic approaches continue to evolve to include both minor and major resections ${ }^{[10]}$. Based on the recommendations from the Second International Consensus Conference on laparoscopic liver resection, 'minor' hepatectomy (e.g., left lateral sectionectomies, resection of segments $4 \mathrm{~B}$, 5, and 6 ) is increasing adopted as a standard practice although high-level evidence based on randomized clinical trials (RCTs) is still pending ${ }^{[11]}$. Techniques for minimally invasive "major" resections are still developing, and no consensus has been adopted, but suffice to say that laparoscopic liver surgery demands a high skill level with advanced experience in both open resection and laparoscopic proficiency. Overall, many highvolume centers perform roughly half of their liver resections minimally invasively.

As the robotic platform expands, experience with robot-assisted liver resection (RALR) has increased dramatically. The robotic approach affords advantages over traditional laparoscopy including optics with increased magnification and the ability to visualize the surgical field with depth perception. In addition, the robotic system allows for greater degrees of freedom in the instruments due to the wrist-like action at joints, facilitating tasks such as suturing for hemorrhage control. For these reasons, it has been suggested that the robotic approach is easier to learn as a method of minimally invasive liver surgery ${ }^{[1]}$. In a review by Salloum et al.$^{[12]}$ summarizing the experience of 447 cases of RALR reported in 14 series, the authors concluded that there is no clear advantage of RALR over conventional laparoscopic hepatectomy at this time, but more vigorous study designs are necessary to draw meaningful conclusions between different techniques. Similar to the costs of laparoscopic surgery, increased intraoperative times and equipment costs of RALR compared to open liver resection are often offset by reduced complications and hospital length of stay. Our own experience indicates that it is a viable alternative to open liver resection even when cost is taken into consideration ${ }^{[13]}$. Reviews of mostly retrospective data have generally found no difference in postoperative outcomes including mortality, morbidity, length of hospitalization, and margin status between laparoscopic and robotic hepatectomy ${ }^{[14-16]}$. Laparoscopic hepatectomy did demonstrate lower blood loss ${ }^{[16]}$ and reduced operative time as well as cost compared to robotic surgery ${ }^{[15]}$. Progress in imaging technology, haptic feedback, vascular control, and artificial intelligence will accelerate the adoption of the robotic platform, and therefore an additional minimally invasive option versus open resection, for hepatobiliary surgery in the future. Once considered a large open operation with significant morbidity, hepatic resection can now be considered a minimally invasive therapy in many instances.

\section{Ablation of hepatic tumors}

The ablation of HCC is another option typically utilized in BCLC o/A-stage tumors that are less than $3 \mathrm{~cm}$ in size. Ablation can be performed using several techniques including thermal, chemical, or non-thermal. Thermal ablation typically consists of radiofrequency ablation (RFA), which is the application of an electrical current through the tissue to generate heat and cause coagulation necrosis. RFA has emerged as the most commonly used ablation technique overall, either via a minimally invasive or open surgical approach. The long-term results are satisfactory with reported local recurrence rates at 5 years ranging from $10 \%-32 \%$ and OS has been shown to be $40 \%-68 \%$ at 5 years ${ }^{[17-24]}$. Several clinical trials have shown it to be superior to percutaneous ethanol injection ${ }^{[25-28]}$. Alternatively, microwave ablation (MWA) uses electromagnetic energy rather than electric current to generate heat, and is less reliant on heat conduction compared to RFA. Both methods report similar local control and complication rates ${ }^{[29]}$. In a RCT of RFA vs. MWA, the local recurrence rate for RFA was found to be $10 \%$ at 2 years compared to $24 \%$ for the MWA group, although this trend was not found to be statistically significant ${ }^{[30]}$. But neither RFA nor MWA should be used when the tumor is adjacent to major vascular or biliary structures, and instead, irreversible 
electroporation (IRE) may be considered for these lesions. IRE involves the application of an electric field above a threshold that causes irreversible damage to the cell membrane but below the threshold causing thermal damage thus minimizing coagulative necrosis. The non-thermal nature of this technique allows potential application when lesions are near important structures ${ }^{[31]}$. Large-scale clinical data remains scarce for this technique, with retrospective studies showing local tumor progression rate within the first year of $20 \%-34 \%{ }^{[32,33]}$ and progression free survival rate of $70 \%$ at 12 month ${ }^{[32,33]}$. Overall, the two thermal ablation techniques (RFA and MWA) appear to provide similar outcomes for patients with HCC lesions less than $3 \mathrm{~cm}$ located away from major vascular or biliary structures and while more data is required, the IRE technique is promising as an alternative for small lesions located next to major structures.

Current practice advocates a minimally invasive approach to liver tumor ablation such that treatments can usually be performed on an out-patient basis. For tumors lying deep in the liver parenchyma, imageguided percutaneous approach is often feasible. However, for lesions that are near the periphery of the liver where it comes within $1 \mathrm{~cm}$ of the visceral structures (e.g., stomach, duodenum, colon, gallbladder, diaphragm), we prefer a laparoscopic approach to safely avoid injuries to such organs. In patients with sub-diaphragmatic lesions (e.g., segment 7,8 ) especially in the setting of multiple prior open abdominal surgeries involving the right upper quadrant, we recommend a minimally invasive thorascopic approach. Open ablations are reserved for patients who are undergoing laparotomies for other indications.

\section{Trans-arterial therapies for HCC}

For patients with multinodular tumors (>3) and those larger than $5 \mathrm{~cm}$ (i.e., BCLC stage B), catheterbased therapies are recommended if otherwise not a resection candidate ${ }^{[34]}$. Options for catheter-based therapies include transarterial bland embolization, chemoembolization (TACE), or radioembolization (TARE) using yttrium-90 (Y90) glass beads. For these patients who have contraindications to undergo resection or ablation, TACE has been demonstrated in RCTs to be superior in terms of survival compared to supportive care ${ }^{[35,36]}$. For Y90 radioembolization, the SARAH trial in Europe did not demonstrate a difference in OS with Y 90 vs. sorafenib as first-line therapy, but did show better local tumor response and improved quality of life, as indicated by lower total and median numbers of treatment-related adverse events in the Y90 group ${ }^{[37]}$. Similarly, SIRveNIB trial in Asia did not demonstrate an OS difference when comparing Y90 radioembolization to sorafenib, but similarly showed increased tolerability to treatment with radioembolization ${ }^{[38]}$. Importantly, liver-directed Y90 treatment was not inferior to sorafenib as firstline therapy for patients with advanced HCC confined to the liver, thus providing meaningful options for these patients.

Comparing lobar TACE with TARE, both methods appear to have similar OS $^{[39-44]}$. Patients undergoing TARE benefit from longer time to progression ${ }^{[43]}$ and progression-free survival ${ }^{[45]}$ compared to TACE with shorter hospitalization stays ${ }^{[41,42]}$. In a comparative effectiveness study of various transarterial strategies based on network meta-analysis, chemo- and radio-embolization provide improved tumor objective response over control (supportive care) and bland embolization, but did not show survival benefit over bland embolization alone ${ }^{[46]}$.

In recent years, there is a trend towards the use of selective, high-dose radioembolization, so-called radiation segmentectomy, for HCCs that receive their arterial supply predominantly from one segmental artery; these lesions tend to be located more peripherally rather than central tumors that often draw blood supply from multiple segmental branches. In the appropriate patients, Y90 segmentectomy is designed to deliver higher radiation dose to the target lesion while sparing more of the non-tumor liver. In a retrospective experience of 178 patients undergoing segmental catheter-based treatments for HCC at our institution, propensity score-matched analysis highlights $92 \%$ complete response of the index lesion following Y 90 segmentectomy compared with $74 \%$ in the TACE group ${ }^{[45]}$. Progression-free survival was 
significantly longer following TARE, but significant OS benefit was not achieved. Larger multi-center experience will be necessary to better inform us of the clinical value of this approach.

\section{Radiation therapy: photons and protons}

Radiation is another modality available in the loco-regional treatment of HCC for patients who are not surgical candidates and in whom catheter-based approaches are not preferred or have failed prior TACE. Bilobar multifocal tumors and proximity to hollow viscus can pose technical challenges to external beam radiotherapy, as with patient with poor liver reserve (e.g., $\geq$ B9) or fluctuating ascites. Historically, the use of external beam radiation therapy (EBRT) was limited by radiation induced liver disease (RILD). The advances in modern technique known as stereotactic body radiation therapy (SBRT) allows for the delivery of more precise radiation to the lesion of interest while sparing normal liver and other structures. Several phase I and II studies of photon SBRT have found favorable local control rates of $78 \%-96 \%$ and OS of $58 \%-94 \%$ at 1 year with acceptable toxicity (8\%-39\% grade 3 or greater, RILD $4 \%-7 \%)^{[47-52]}$. While SBRT relies on photons to deliver radiation dose, charged particles such as protons have emerged as an alternative technique to deliver radiation. The advantage of proton beam therapy is the ability to control the energy along its beam path, thus minimizing the exit dose. This allows for precise delivery of the radiation dose to the lesion and sparing greater liver parenchyma. Phase I/II studies using proton therapy found 2 to 3 year OS of 50\%-63\% with 0\%-6\% grade 3 or greater toxicities ${ }^{[53-56]}$. No RCT has been performed directly comparing photon SBRT and proton beam therapy, but both modalities appear safe and effective in the treatment of HCC. The enormous cost of installing a proton center limits its widespread use. Nonetheless, modern techniques in external beam radiotherapy has emerged as an effective alternative for the local control of HCC in patients who are not suitable to undergo resection or ablation.

\section{COMPARISON OF MODALITIES FOR LOCO-REGIONAL TREATMENT OF HCC}

\section{Resection vs. ablation}

For patients who are stage BCLC 0 and $\mathrm{A}$, resection and ablation are recommended as treatment modalities. Several prospective RCTs have attempted to evaluate which of the two modalities, if any, is superior. An early study from China investigated percutaneous ablation vs. open surgical resection and found statistically equivalent OS of $68 \%$ and $64 \%$ respectively, as well as statistically equivalent DFS rates of $46 \%$ and $52 \%$ respectively ${ }^{[57]}$. Greater morbidity and the only death reported in the study occurred in the surgical group. A second RCT from China, in contrast, found that 5-year OS was higher in the open resection group compared to the percutaneous RFA group ( $75 \% v s .55 \%$, respectively) with lower recurrence rates of resection compared to the RFA group ( $42 \%$ and $63 \%$, respectively) ${ }^{[58]}$. However, the open resection group had a greater rate of adverse events than the RFA group. A third study again from China comparing percutaneous RFA with open hepatectomy did not find a difference in 3 year OS between RFA and resection ( $67 \%$ vs. $75 \%$, respectively), with no difference in the recurrence rate at 3 years (38\% vs. 50\% for resection and RFA, respectively) but a higher complication rate in the resection group ${ }^{[59]}$. A more recent study from Hong Kong which included long term follow-up to 10 years, showed statistically similar OS of $48 \%$ in the open resection group and $42 \%$ for the RFA group. Recurrence-free survival was $29 \%$ in the resection group and $18 \%$ in the RFA group, which did not meet statistical significance ${ }^{[60]}$. In this study, the postoperative complication rate did not differ between the two although RFA did have shorter length of stay. Taking all prospective RCTs into account, it appears that the survival and recurrence rates are similar between RFA and resection, especially for smaller tumors (i.e., $\leq 3 \mathrm{~cm}$ ) with the added benefit of fewer complications with ablation. However, no trial has evaluated the outcome of ablation against those of laparoscopic or robotic hepatectomy, which is expected to have lower morbidity compared to open resection. Other factors include methods of ablation such that higher local recurrence has been reported following percutaneous ablation compared with laparoscopic or open procedure. Collectively, for HCCs $\leq 3 \mathrm{~cm}$, clinical outcomes are comparable between ablation and resection, thus selection between the two modalities lies with providers' experience and patients' preference. Our institutional bias is to 
offer a minimally invasive approach for either ablation or resection that will provide optimal local control while preserving liver reserve.

\section{Resection vs. TACE}

As trans-catheter based techniques developed in managing HCC, the effectiveness of TACE was evaluated against resection as the standard. To date, one RCT in China has been performed directly comparing the two treatment modalities in patients with multiple resectable HCC lesions that fell outside of the Milan criteria. The 3-year OS was significantly higher in the hepatectomy group at $52 \%$, compared to $18 \%$ in the TACE group ${ }^{[6]]}$. Similar results are reported in several propensity score matched non-randomized clinical trials, all showing an overall statistically significant improved OS with resection (18\%-54\% at 5 years) compared to TACE (12\%-34\% at 5 years) ${ }^{[62-66]}$. A recent meta-analysis which included an additional 12 nonrandomized controlled trials also found improved OS, 1-, 3-, and 5-year OS with resection compared to TACE with equivalent procedure related mortality ${ }^{[66]}$. Across all studies, the findings of improved survival after resection compared to TACE were consistent across BCLC stages studied. Therefore, in patients with resectable HCC, hepatectomy is superior to TACE, however, there exists a role of catheter-based approaches in patients with potentially resectable HCC but with limited hepatic reserve.

\section{Ablation vs. TACE}

In patients with HCC who are not resection candidates, other treatment options of the loco-regional disease include ablation or catheter-based approaches. While no RCT has been performed comparing the two, they have been compared using propensity-score matching analysis in retrospective studies. A retrospective study from Taiwan found that in patients within the Milan criteria (single tumor less than $5 \mathrm{~cm}$, or 3 or fewer nodules less than $3 \mathrm{~cm}$ ) with performance status of 0 , OS was significantly better in the RFA group compared to the TACE with drug eluting beads group ( $77 \%$ vs. $62 \%$ at 3 years, respectively ${ }^{[67]}$. In patients with worse performance status $(\geq 1)$, survival difference was no longer evident. In other retrospective studies from China and Japan, RFA improved survival of BCLC 0/A patients compared with patients who were also BCLC 0/A but instead received TACE, but this difference was attributable to differences in co-morbidities between the two groups ${ }^{[68,69]}$. One of these studies did find that the cumulative recurrence rate was higher following TACE. Currently when HCC is unresectable but ablatable, thermal ablation remains the treatment of choice in BCLC o/A patients. Otherwise, TACE is a viable alternative in providing a survival benefit over supportive care.

\section{Radiation therapy vs. other loco-regional treatments}

Radiation therapy has grown in popularity for its potential uses in loco-regional management of HCC. Few retrospective studies have evaluated radiation $v s$. ablation; a propensity matched analysis based on SEER database (2004-2012) found that ablation was associated with improved survival compared to EBRT in patients with tumors greater than $3 \mathrm{~cm}$, while EBRT and ablation were equivalent in patients with tumors less than $3 \mathrm{~cm}^{[70]}$. A separate retrospective study of SBRT $v s$. RFA also showed no significant difference in survival between SBRT and RFA, nor time to progression for tumors less than $2 \mathrm{~cm}^{[7]]}$. However, for larger tumors, it reported the opposite findings with improved time to local progression in the SBRT group vs. the RFA group. One RCT has been performed comparing proton therapy to TACE therapy for HCC meeting transplant criteria. Results of an interim analysis demonstrated no difference in OS at 2 years, but there is a trend towards improved progression-free survival and local tumor control favoring the proton radiation therapy group ${ }^{[72]}$. Further prospective evidence is needed in order to draw conclusions about the effectiveness of radiation therapy, but the data thus far indicates it will play a major role in the management of HCC.

\section{SELECTION OF TREATMENT MODALITY}

With the expansion of options that are currently employed in loco-regional management of HCC, clinicians are faced with the challenge of selecting the most appropriate treatment for individual patients. In the era of 
Table 1. Compilation and comparison of reported data from prospective clinical studies

\begin{tabular}{|c|c|c|c|}
\hline Treatment modality & Local control & Overall survival at 1 year & Rate of adverse events (grade $\geq 3^{\prime}$ ) \\
\hline Open surgical resection ${ }^{[57-61,78]}$ & $96 \%-99 \%$ & $93 \%-98 \%$ & $16 \%-55 \%$ \\
\hline Percutaneous or laparoscopic ablation ${ }^{t 26,30,57-60,78]}$ & $87 \%-96 \%$ & $87 \%-98 \%$ & $4 \%-9 \%$ \\
\hline TACE or TARE" ${ }^{* 36-38,61,72]}$ & $45 \%-68 \%$ & $40 \%-77 \%$ & $7 \%-54 \%$ \\
\hline External radiation ${ }^{* *[}[47,48,72]$ & $78 \%-96 \%$ & $58 \%-94 \%$ & $0-39 \%$ \\
\hline
\end{tabular}

"Based on the Clavien-Dindo classification system; "predominately radiofrequency ablation rather than MWA; "these studies use largely nonselective techniques (e.g., lobar treatment); "'both photon and proton radiotherapy included. TACE: transarterial chemoembolization; TARE: transarterial radioembolization; MWA: microwave ablation

personalized medicine, the spectrum of minimally invasive liver-directed therapies outlined above allows for a greater number of patients to potentially benefit from these survival-prolonging treatments. Advances in precise tumor targeting have led to better preservation of hepatic function in patients with underlying liver disease; this is particularly relevant to those who are not transplant candidates. Based on current evidence, the rates of local tumor control following hepatic resection, thermal ablation, and external beam radiation therapy are approaching parity for small HCCs, but there has not been any direct comparison across all modalities to account for confounders, and long-term results are lacking for the newer techniques [Table 1]. Excluding transplantation, which benefits a small fraction of patients, surgical resection offers the best chance of cure while the results of thermal ablation for $\mathrm{HCC} \leq 3 \mathrm{~cm}$ is on par with that of hepatectomy. At present, both modalities are considered curative with the major difference between the two being the severity of treatment-related morbidity, but through the use of laparoscopic or robotic liver resection, the gap has been minimized. The choice between resection and ablation for small HCCs comes down to provider's preference based on tumor location, liver reserve and co-morbidities. For those who are at higher risk for general anesthesia, radiation, either internal (Y90) or external (SBRT), offers excellent local control. While these options are considered palliative in the past, current evidence using selective Y90 segmentectomy and SBRT/proton radiation yield approximately $90 \%$ local control at 2 years. Currently, there are only a handful of studies using radiation segmentectomy reporting such high rates of success, but if confirmed in larger long-term studies, radiation may carry similar efficacy as ablation or resection. Results from on-going trials will better define the role of these modalities, but if they live up to their expectations, clinicians will have the luxury to offer a variety of minimally invasive treatment options that best suit the patient and his/her clinical scenario including factors related to the tumor, liver reserve, performance status, as well as cost and social circumstances. The large socioeconomic impact of new therapies has led to financial toxicity for many patients diagnosed with cancer, which can limit access and treatment adherence leading to adverse outcome $^{[73]}$. Greater emphasis on fiscally responsible care is particularly relevant to HCC management given the wide disparity in the cost of surgery, ablation, radiation and systemic therapies. Based on Markov modelling, it has been suggested that RFA is more cost-effective than SBRT as the initial management of unresectable HCC, however, for recurrent disease, SBRT was favored over repeat RFA ${ }^{[7]}$. Another study demonstrated that the addition of TACE to sorafenib or non-sorafenib chemotherapy is more cost effective than systemic therapy alone ${ }^{[75]}$. As the financial burden rises, some resources may become limiting, and physicians and their patients will need to have open discussions regarding the wise utilization of available options that meet their personal goals.

In summary, loco-regional treatments of HCC are improving across all disciplines. Current and future directions include the investigation of combination strategies. For example, a number of trials have examined the addition of radiation therapy to TACE, which was shown to have improved OS and progression free survival in patients with macroscopic vascular invasion compared to sorafenib ${ }^{[76]}$. Combination TACE plus radiation therapy also showed improved rate of complete response and DFS compared to TACE alone ${ }^{[77]}$. Further, the combined use of minimally invasive loco-regional therapies and systemic drugs such as kinase inhibitors and immunotherapies is also being examined with the hope of improving the chance of cancer-free survival while preserving quality of living. 


\section{DECLARATIONS}

\section{Authors' contributions}

Contributed to all aspects of the article including topics of coverage, format of discussion, writing and editing of the manuscript: Sullivan KM, Yeung RS

\section{Availability of data and materials}

Not applicable.

\section{Financial support and sponsorship}

None.

\section{Conflicts of interest}

All authors declared that there are no conflicts of interest.

\section{Ethical approval and consent to participate}

Not applicable.

\section{Consent for publication}

Not applicable.

\section{Copyright}

(c) The Author(s) 2018.

\section{REFERENCES}

1. Collaboration GBoDLC. The burden of primary liver cancer and underlying etiologies from 1990 to 2015 at the global, regional, and national level: results from the global burden of disease study 2015. JAMA Oncol 2017;3:1683-91.

2. Ryerson AB, Eheman CR, Altekruse SF, Ward JW, Jemal A, et al. Annual Report to the Nation on the Status of Cancer, 1975-2012, featuring the increasing incidence of liver cancer. Cancer 2016;122:1312-37.

3. Cherqui D, Husson E, Hammoud R, Malassagne B, Stephan F, et al. Laparoscopic liver resections: a feasibility study in 30 patients. Ann Surg 2000;232:753-62.

4. Koffron AJ, Auffenberg G, Kung R, Abecassis M. Evaluation of 300 minimally invasive liver resections at a single institution: less is more. Ann Surg 2007;246:385-92; discussion 92-4.

5. Nguyen KT, Gamblin TC, Geller DA. World review of laparoscopic liver resection-2,804 patients. Ann Surg 2009;250:831-41.

6. Rao A, Rao G, Ahmed I. Laparoscopic vs. open liver resection for malignant liver disease. A systematic review. Surgeon 2012;10:194-201.

7. Vigano L, Tayar C, Laurent A, Cherqui D. Laparoscopic liver resection: a systematic review. J Hepatobiliary Pancreat Surg 2009;16:410-21.

8. Bagante F, Spolverato G, Strasberg SM, Gani F, Thompson V, et al. Minimally invasive vs. open hepatectomy: a comparative analysis of the national surgical quality improvement program database. J Gastrointest Surg 2016;20:1608-17.

9. Parks KR, Kuo YH, Davis JM, O’ Brien B, Hagopian EJ. Laparoscopic versus open liver resection: a meta-analysis of long-term outcome. HPB (Oxford) 2014;16:109-18.

10. Thornblade LW, Shi X, Ruiz A, Flum DR, Park JO. Comparative effectiveness of minimally invasive surgery and conventional approaches for major or challenging hepatectomy. J Am Coll Surg 2017;224:851-61.

11. Wakabayashi G, Cherqui D, Geller DA, Buell JF, Kaneko H, et al. Recommendations for laparoscopic liver resection: a report from the second international consensus conference held in Morioka. Ann Surg 2015;261:619-29.

12. Salloum C, Lim C, Malek A, Compagnon P, Azoulay D. Robot-assisted laparoscopic liver resection: a review. J Visc Surg 2016;153:447-56.

13. Sham JG, Richards MK, Seo YD, Pillarisetty VG, Yeung RS, et al. Efficacy and cost of robotic hepatectomy: is the robot cost-prohibitive? J Robot Surg 2016;10:307-13.

14. Jackson NR, Hauch A, Hu T, Buell JF, Slakey DP, et al. The safety and efficacy of approaches to liver resection: a meta-analysis. Jsls 2015;19:e2014.00186.

15. Qiu J, Chen S, Chengyou D. A systematic review of robotic-assisted liver resection and meta-analysis of robotic versus laparoscopic hepatectomy for hepatic neoplasms. Surg Endosc 2016;30:862-75.

16. Montalti R, Berardi G, Patriti A, Vivarelli M, Troisi RI. Outcomes of robotic vs laparoscopic hepatectomy: a systematic review and metaanalysis. World J Gastroenterol 2015;21:8441-51.

17. Sandro R, Valentina R, Laura R, Giorgia G, Torello VF, et al. Repeated radiofrequency ablation for management of patients with cirrhosis with small hepatocellular carcinomas: a long-term cohort study. Hepatology 2011;53:136-47.

18. Shiina S, Tateishi R, Arano T, Uchino K, Enooku K, et al. Radiofrequency ablation for hepatocellular carcinoma: 10-year outcome and prognostic factors. Am J Gastroenterol 2011;107:569.

19. Kim YS, Lim HK, Rhim H, Lee MW, Choi D, et al. Ten-year outcomes of percutaneous radiofrequency ablation as first-line therapy of early 
hepatocellular carcinoma: analysis of prognostic factors. J Hepatol 2013;58:89-97.

20. Lencioni R, Cioni D, Crocetti L, Franchini C, Pina CD, et al. Early-stage hepatocellular carcinoma in patients with cirrhosis: long-term results of percutaneous image-guided radiofrequency ablation. Radiology 2005;234:961-7.

21. Lee DH, Lee JM, Lee JY, Kim SH, Yoon JH, et al. Radiofrequency ablation of hepatocellular carcinoma as first-line treatment: long-term results and prognostic factors in 162 patients with cirrhosis. Radiology 2014;270:900-9.

22. N'Kontchou G, Mahamoudi A, Aout M, Ganne-Carrié N, Grando V, et al. Radiofrequency ablation of hepatocellular carcinoma: long-term results and prognostic factors in 235 Western patients with cirrhosis. Hepatology 2009;50:1475-83.

23. Francica G, Saviano A, De Sio I, De Matthaeis N, Brunello F, et al. Long-term effectiveness of radiofrequency ablation for solitary small hepatocellular carcinoma: a retrospective analysis of 363 patients. Dig Liver Dis 2013;45:336-41.

24. Brunello F, Cantamessa A, Gaia S, Carucci P, Rolle E, et al. Radiofrequency ablation: technical and clinical long-term outcomes for single hepatocellular carcinoma up to $30 \mathrm{~mm}$. Eur J Gastroen Hepat 2013;25:842-9.

25. Lin SM, Lin CJ, Lin CC, Hsu CW, Chen YC. Radiofrequency ablation improves prognosis compared with ethanol injection for hepatocellular carcinoma $<$ or $=4 \mathrm{~cm}$. Gastroenterology 2004;127:1714-23.

26. Lin SM, Lin CJ, Lin CC, Hsu CW, Chen YC. Randomised controlled trial comparing percutaneous radiofrequency thermal ablation, percutaneous ethanol injection, and percutaneous acetic acid injection to treat hepatocellular carcinoma of $3 \mathrm{~cm}$ or less. Gut 2005;54:1151-6.

27. Shiina S, Teratani T, Obi S, Sato S, Tateishi R, et al. A randomized controlled trial of radiofrequency ablation with ethanol injection for small hepatocellular carcinoma. Gastroenterology 2005;129:122-30.

28. Lencioni RA, Allgaier HP, Cioni D, Olschewski M, Deibert P, et al. Small hepatocellular carcinoma in cirrhosis: randomized comparison of radio-frequency thermal ablation versus percutaneous ethanol injection. Radiology 2003;228:235-40.

29. Abdelaziz A, Elbaz T, Shousha HI, Mahmoud S, Ibrahim M, et al. Efficacy and survival analysis of percutaneous radiofrequency versus microwave ablation for hepatocellular carcinoma: an Egyptian multidisciplinary clinic experience. Surg Endosc 2014;28:3429-34.

30. Shibata T, Iimuro Y, Yamamoto Y, Maetani Y, Ametani F, et al. Small hepatocellular carcinoma: comparison of radio-frequency ablation and percutaneous microwave coagulation therapy. Radiology 2002;223:331-7.

31. Cannon R, Ellis S, Hayes D, Narayanan G, Martin RC, 2nd. Safety and early efficacy of irreversible electroporation for hepatic tumors in proximity to vital structures. J Surg Oncol 2013;107:544-9.

32. Sutter O, Calvo J, N'Kontchou G, Nault JC, Ourabia R, et al. Safety and efficacy of irreversible electroporation for the treatment of hepatocellular carcinoma not amenable to thermal ablation techniques: a retrospective single-center case series. Radiology 2017;284:877-86.

33. Fruhling P, Nilsson A, Duraj F, Haglund U, Noren A. Single-center nonrandomized clinical trial to assess the safety and efficacy of irreversible electroporation (IRE) ablation of liver tumors in humans: Short to mid-term results. Eur J Surg Oncol 2017;43:751-7.

34. EASL-EORTC clinical practice guidelines: management of hepatocellular carcinoma. J Hepatol 2012;56:908-43.

35. Llovet JM, Real MI, Montana X, Planas R, Coll S, et al. Arterial embolisation or chemoembolisation versus symptomatic treatment in patients with unresectable hepatocellular carcinoma: a randomised controlled trial. Lancet 2002;359:1734-9.

36. Lo CM, Ngan H, Tso WK, Liu CL, Lam CM, et al. Randomized controlled trial of transarterial lipiodol chemoembolization for unresectable hepatocellular carcinoma. Hepatology 2002;35:1164-71.

37. Vilgrain V, Pereira H, Assenat E, Guiu B, Ilonca AD, et al. Efficacy and safety of selective internal radiotherapy with yttrium-90 resin microspheres compared with sorafenib in locally advanced and inoperable hepatocellular carcinoma (SARAH): an open-label randomised controlled phase 3 trial. Lancet Oncol 2017;18:1624-36.

38. Chow PKH, Gandhi M, Tan SB, Khin MW, Khasbazar A, et al. SIRveNIB: selective internal radiation therapy Versus Sorafenib in AsiaPacific patients with hepatocellular carcinoma. J Clin Oncol 2018; doi: 10.1200/jco.2017.76.0892:Jco2017760892.

39. McDevitt JL, Alian A, Kapoor B, Bennett S, Gill A, et al. Single-center comparison of overall survival and toxicities in patients with infiltrative hepatocellular carcinoma treated with Yttrium-90 radioembolization or drug-eluting embolic transarterial chemoembolization. J Vasc Interv Radiol 2017;28:1371-7.

40. Akinwande O, Kim D, Edwards J, Brown R, Philips P, et al. Is radioembolization ((90)Y) better than doxorubicin drug eluting beads (DEBDOX) for hepatocellular carcinoma with portal vein thrombosis? A retrospective analysis. Surg Oncol 2015;24:270-5.

41. Moreno-Luna LE, Yang JD, Sanchez W, Paz-Fumagalli R, Harnois DM, et al. Efficacy and safety of transarterial radioembolization versus chemoembolization in patients with hepatocellular carcinoma. Cardiovase Intervent Radiol 2013;36:714-23.

42. Lance C, McLennan G, Obuchowski N, Cheah G, Levitin A, et al. Comparative analysis of the safety and efficacy of transcatheter arterial chemoembolization and yttrium-90 radioembolization in patients with unresectable hepatocellular carcinoma. J Vasc Interv Radiol 2011;22:1697-705

43. Salem R, Gordon AC, Mouli S, Hickey R, Kallini J, et al. Y90 radioembolization significantly prolongs time to progression compared with chemoembolization in patients with hepatocellular carcinoma. Gastroenterology 2016;151:1155-63.e2.

44. Kooby DA, Egnatashvili V, Srinivasan S, Chamsuddin A, Delman KA, et al. Comparison of yttrium- 90 radioembolization and transcatheter arterial chemoembolization for the treatment of unresectable hepatocellular carcinoma. J Vasc Interv Radiol 2010;21:224-30.

45. Padia SA, Johnson GE, Horton KJ, Ingraham CR, Kogut MJ, et al. Segmental Yttrium-90 radioembolization versus segmental chemoembolization for localized hepatocellular carcinoma: results of a single-center, retrospective, propensity score-matched study. J Vasc Interv Radiol 2017;28:777-85.e1.

46. Katsanos K, Kitrou P, Spiliopoulos S, Maroulis I, Petsas T, et al. Comparative effectiveness of different transarterial embolization therapies alone or in combination with local ablative or adjuvant systemic treatments for unresectable hepatocellular carcinoma: a network metaanalysis of randomized controlled trials. PLoS One 2017;12:e0184597.

47. Kang JK, Kim MS, Cho CK, Yang KM, Yoo HJ, et al. Stereotactic body radiation therapy for inoperable hepatocellular carcinoma as a local salvage treatment after incomplete transarterial chemoembolization. Cancer 2012;118:5424-31.

48. Bujold A, Massey CA, Kim JJ, Brierley J, Cho C, et al. Sequential phase I and II trials of stereotactic body radiotherapy for locally advanced 
hepatocellular carcinoma. J Clin Oncol 2013;31:1631-9.

49. Lasley FD, Mannina EM, Johnson CS, Perkins SM, Althouse S, et al. Treatment variables related to liver toxicity in patients with hepatocellular carcinoma, Child-Pugh class A and B enrolled in a phase 1-2 trial of stereotactic body radiation therapy. Pract Radiat Oncol 2015;5:e443-e9.

50. Weiner AA, Olsen J, Ma D, Dyk P, DeWees T, et al. Stereotactic body radiotherapy for primary hepatic malignancies - report of a phase I/II institutional study. Radiother Oncol 2016;121:79-85.

51. Takeda A, Sanuki N, Tsurugai Y, Iwabuchi S, Matsunaga K, et al. Phase 2 study of stereotactic body radiotherapy and optional transarterial chemoembolization for solitary hepatocellular carcinoma not amenable to resection and radiofrequency ablation. Cancer 2016;122:2041-9.

52. Kim JW, Seong J, Lee IJ, Woo JY, Han KH. Phase I dose escalation study of helical intensity-modulated radiotherapy-based stereotactic body radiotherapy for hepatocellular carcinoma. Oncotarget 2016;7:40756-66.

53. Fukumitsu N, Sugahara S, Nakayama H, Fukuda K, Mizumoto M, et al. A prospective study of hypofractionated proton beam therapy for patients with hepatocellular carcinoma. Int J Radiat Oncol 2009;74:831-6.

54. Kawashima M, Furuse J, Nishio T, Konishi M, Ishii H, et al. Phase II study of radiotherapy employing proton beam for hepatocellular carcinoma. J Clin Oncol 2005;23:1839-46.

55. Bush DA, Kayali Z, Grove R, Slater JD. The safety and efficacy of high-dose proton beam radiotherapy for hepatocellular carcinoma: a phase 2 prospective trial. Cancer 2011;117:3053-9.

56. Hong TS, Wo JY, Yeap BY, Ben-Josef E, McDonnell EI, et al. Multi-institutional phase II study of high-dose hypofractionated proton beam therapy in patients with localized, unresectable hepatocellular carcinoma and intrahepatic cholangiocarcinoma. J Clin Oncol 2016;34:460-8.

57. Chen MS, Li JQ, Zheng Y, Guo RP, Liang HH, et al. A prospective randomized trial comparing percutaneous local ablative therapy and partial hepatectomy for small hepatocellular carcinoma. Ann Surg 2006;243:321-8.

58. Huang J, Yan L, Cheng Z, Wu H, Du L, et al. A randomized trial comparing radiofrequency ablation and surgical resection for HCC conforming to the Milan criteria. Ann Surg 2010;252:903-12.

59. Feng K, Yan J, Li X, Xia F, Ma K, et al. A randomized controlled trial of radiofrequency ablation and surgical resection in the treatment of small hepatocellular carcinoma. J Hepatol 2012;57:794-802.

60. Ng KKC, Chok KSH, Chan ACY, Cheung TT, Wong TCL, et al. Randomized clinical trial of hepatic resection versus radiofrequency ablation for early-stage hepatocellular carcinoma. Br J Surg 2017;104:1775-84.

61. Yin L, Li H, Li AJ, Lau WY, Pan ZY, et al. Partial hepatectomy vs. transcatheter arterial chemoembolization for resectable multiple hepatocellular carcinoma beyond Milan criteria: a RCT. J Hepatol 2014;61:82-8.

62. Yuan BH, Yuan WP, Li RH, Xiang BD, Gong WF, et al. Propensity score-based comparison of hepatic resection and transarterial chemoembolization for patients with advanced hepatocellular carcinoma. Tumour Biol 2016;37:2435-41.

63. Liu PH, Hsia CY, Lee YH, Hsu CY, Huang YH, et al. Surgical resection versus transarterial chemoembolization for BCLC stage C hepatocellular carcinoma. J Surg Oncol 2015;111:404-9.

64. Zhong JH, Ke Y, Gong WF, Xiang BD, Ma L, et al. Hepatic resection associated with good survival for selected patients with intermediate and advanced-stage hepatocellular carcinoma. Ann Surg 2014;260:329-40.

65. Tada T, Kumada T, Toyoda H, Tsuji K, Hiraoka A, et al. Role of hepatic resection in patients with intermediate-stage hepatocellular carcinoma: a multicenter study from Japan. Cancer Sci 2017;108:1414-20.

66. Hyun MH, Lee YS, Kim JH, Lee CU, Jung YK, et al. Hepatic resection compared to chemoembolization in intermediate- to advanced-stage hepatocellular carcinoma: a meta-analysis of high-quality studies. Hepatology 2018; doi: 10.1002/hep.29883.

67. Liu PH, Lee YH, Hsu CY, Huang YH, Chiou YY, et al. Survival advantage of radiofrequency ablation over transarterial chemoembolization for patients with hepatocellular carcinoma and good performance status within the Milan criteria. Ann Surg Oncol 2014;21:3835-43.

68. Chen RX, Gan YH, Ge NL, Chen Y, Ma H, et al. Comparison of transarterial chemoembolization with radiofrequency ablation for unresectable Barcelona Clinic Liver Cancer stage 0/A hepatocellular carcinoma: a propensity score matching. J Gastroenterol Hepatol 2016;31:442-9.

69. Ishikawa K, Chiba T, Ooka Y, Suzuki E, Ogasawara S, et al. Transarterial chemoembolization as a substitute to radiofrequency ablation for treating Barcelona Clinic Liver Cancer stage 0/A hepatocellular carcinoma. Oncotarget 2018;9:21560-8.

70. Berger NG, Tanious MN, Hammad AY, Miura JT, Mogal H, et al. External radiation or ablation for solitary hepatocellular carcinoma: a survival analysis of the SEER database. J Surg Oncol 2017;116:307-12.

71. Wahl DR, Stenmark MH, Tao Y, Pollom EL, Caoili EM, et al. Outcomes after stereotactic body radiotherapy or radiofrequency ablation for hepatocellular carcinoma. J Clin Oncol 2016;34:452-9.

72. Bush DA, Smith JC, Slater JD, Volk ML, Reeves ME, et al. Randomized clinical trial comparing proton beam radiation therapy with transarterial chemoembolization for hepatocellular carcinoma: results of an interim analysis. Int J Radiat Oncol Biol Phys 2016;95:477-82.

73. Gilligan AM, Alberts DS, Roe DJ, Skrepnek GH. Death or Debt? National Estimates of Financial Toxicity in Persons with NewlyDiagnosed Cancer. Am J Med 2018; doi: 10.1016/j.amjmed.2018.05.020.

74. Pollom EL, Lee K, Durkee BY, Grade M, Mokhtari DA, et al. Cost-effectiveness of stereotactic body radiation therapy versus radiofrequency ablation for hepatocellular carcinoma: a markov modeling study. Radiology 2017;283:460-8.

75. Thein H-H, Qiao Y, Zaheen A, Jembere N, Sapisochin G, et al. Cost-effectiveness analysis of treatment with non-curative or palliative intent for hepatocellular carcinoma in the real-world setting. PLOS ONE 2017;12:e0185198.

76. Yoon SM, Ryoo BY, Lee SJ, Kim JH, Shin JH, et al. Efficacy and safety of transarterial chemoembolization plus external beam radiotherapy vs sorafenib in hepatocellular carcinoma with macroscopic vascular invasion: a randomized clinical trial. JAMA Oncol 2018;4:661-9.

77. Honda Y, Kimura T, Aikata H, Kobayashi T, Fukuhara T, et al. Stereotactic body radiation therapy combined with transcatheter arterial chemoembolization for small hepatocellular carcinoma. J Gastroenterol Hepatol 2013;28:530-6.

78. Fang Y, Chen W, Liang X, Li D, Lou H, et al. Comparison of long-term effectiveness and complications of radiofrequency ablation with hepatectomy for small hepatocellular carcinoma. J Gastroenterol Hepatol 2014;29:193-200. 